\begin{tabular}{|c|c|c|}
\hline & Int.J.Curr.Microbiol.App.Sci (2021) 10(10): 614-621 & \\
\hline & $\begin{array}{l}\text { International Journal of Current Microbiology and Applied Sciences } \\
\text { ISSN: 2319-7706 Volume } \mathbf{1 0} \text { Number } \mathbf{1 0}(\mathbf{2 0 2 1 )} \\
\text { Journal homepage: } \underline{\text { http://www.ijcmas.com }}\end{array}$ & 30 \\
\hline $\begin{array}{l}\text { EXCELLENT } \\
\text { PUBLISHERS }\end{array}$ & & \\
\hline
\end{tabular}

Original Research Article

https://doi.org/10.20546/ijcmas.2021.1010.071

\title{
Prevalence of Breast-Feeding Practices among Post Natal Mothers
}

\author{
Vandana Gupta* \\ Department of Home Science, Dev Samaj College for Women, Ferozepur City, Punjab, India \\ *Corresponding author
}

A B S T R A C T

\section{Keywords}

Exclusive Breast

Feeding,

Knowledge,

Maternal Attitude,

formula feeding

Article Info

Accepted:

20 September 2021

Available Online:

10 October 2021
Breastfeeding is one of the most important determinants of child survival, birth spacing, and prevention of childhood infections. The WHO recommends that for the first six months of life, infants should be exclusively breastfed to achieve optimal growth, development, and health. A number of studies have been assessed regarding knowledge, attitude and breastfeeding practices in different parts of the world; such studies are limited among Indian mothers. Especially the studies on breastfeeding awareness, knowledge and maternal attitude are also a concept of interest to health professionals who support breastfeeding. Therefore, this community based cross sectional study was undertaken to examine the infant feeding practices, knowledge and attitude towards breast feeding among Indian postnatal mothers residing in urban and well as rural areas of Ferozepur district. On the basis of random sampling technique 300 respondents were selected from the Ferozepur district which was further divided into six different blocks (Guruharsahai, Zira, Makhu, Ghalkhurd, Mamdot and Ferozepur cantt. Higher educational qualification leads to increased mean awareness score pertaining to breast feeding of nursing respondents $(\mathrm{p}<0.01)$ There is pertinent need to spread awareness in their local language regarding specific terms like "exclusive breast feeding" and "infant formula feeding" among nursing mothers.

\section{Introduction}

Human milk is universally acknowledged as the best and complete food for infants including sick and preterm as it fulfils their specific nutritional needs. Breastfeeding during infancy has particular importance because it is essential for survival, growth, development, and health of infants (Joseph et al., 2012). Since it suffices most of the nutritional requirements, breast milk is considered the best food for the growing infant if given sufficiently and in an appropriate way. Breast milk has the best potential to help the babies grow well in later stages of childhood. The protective benefits of breast milk for neonates and mothers are well documented in studies conducted in both developed and developing countries among different socio-economic strata of the society (Chandhiok, 2015). The infant feeding with human milk not including the addition of any 
other liquids or solids known as Exclusive Breastfeeding. The benefits of breast-feeding, to both baby and mother, have long been recognized. Exclusive breastfeeding for the first six months of life followed by safe complementary foods and nutritionally adequate with continued breastfeeding up to 2 years of age or beyond is the recommended practice by American of Pediatrics and World Health Organization.

A recent meta-analysis concluded that women who had ever breastfed and who breastfed for longer duration have a lower risk of breast and ovarian carcinoma and also type 2 diabetes mellitus. Exclusive breastfeeding and predominant breastfeeding during the first six months postpartum increase the duration of lactational amenorrhoea. Thus, for poor countries where the prevalence of contraceptive use is low, appropriately managed breastfeeding is a key component of reproductive health program (Chandhiok, 2015).

The United Nations Children's Fund (UNICEF) and World Health Organization (WHO) suggested that breast milk as the best food for the infant and that feeding should be initiated immediately after birth and continued to 6 months. With appropriate supplementary foods, breastfeeding can continue up to 2 years old and beyond. Despite strong evidences in support of exclusive breast feeding for the first six months of life, its acceptance has remained low worldwide and it is estimated that only about one-third of infants are exclusively breastfed during the starting period of their life. India comprises almost $13.1 \%$ of child population aged $0-6$ years. Children of today are tomorrow's citizens; India accounts for almost $43 \%$ underweight children as against $32 \%$ in Pakistan, 9\% in South Africas. According to UNICEF's State of the World's Children 2012 , only $43 \%$ of the children born are initiated into breastfeeding early, only $37 \%$ are exclusively breast fed for 3 months, only $60 \%$ get adequate and appropriate complimentary foods at 6-8 months and just $55 \%$ continue to be breastfed for at least two years (Kramer et al., 2003).

Breastfeeding is one of the smartest investments that any country/ society can make to ensure a healthy, equitable and sustainable future. As is well documented that mother's milk provides a blanket protection to the child from various minor and major health and developmental problems and complications, but the information on the prevalence rate of breastfeeding and factors influencing the breastfeeding practices is limited, especially in the rural and far-flung areas of India.

A number of studies have examined the different breastfeeding practices in different part of world, but this type of studies are limited among Indian postnatal mothers. Especially studies on breastfeeding knowledge, practices, attitude of mothers, maternal attitude are also concept of interest to health professionals who support breast feeding.

The objective of this research paper is to assess the prevalence and examine various practices associated with exclusive breastfeeding during the first six months of life among mothers in urban and rural areas of Ferozepur City of Punjab- a backward and border city of India

The main objectives include to study the breastfeeding practices prevalent and nutritional status of both mother and child. Also to assess the prevalence of exclusive breastfeeding practices amongst the target group.

Mohamed et al., (2018) investigated the 
association between maternal knowledge and attitudes and EBF and compared the knowledge, attitude and practices between primiparous and multiparous mothers at Wajir County Hospital, Wajir County in Kenya. Exclusive breastfeeding (EBF) is recommended for 6 months of age, with continued breastfeeding for 2 years of age or beyond. 281 mothers were selected through structured researcher administered questionnaires and collected information on maternal KAP on EBF questionnaires, recruited from a maternal and child health centre in 2014; primiparous $(\mathrm{n}=137)$ and multiparous $(\mathrm{n}=144)$ with infants $0-5$ months of age. The result revealed that prevalence of EBF among infants $0-5$ months old was 45.5 percent. The rate of EBF among primiparous mothers was 39.4 percent and 49.3 percent was multiparous mothers. The knowledge score on breastfeeding for the primiparous mothers was $7.93 \pm 2.10$ and $7.49 \pm 2.20$ for the multiparous mothers. The mean attitude score for the primiparous mothers was $29.46 \pm$ 5.65 and $28.65 \pm 6.40$ for the multiparous mothers. The prevalence of EBF, maternal knowledge and attitudes towards breastfeeding was similar among the two groups of mothers.

It concluded that positive attitudes towards breastfeeding were associated with exclusive breastfeeding but maternal knowledge was not. Efforts to promote exclusive breastfeeding should, in addition to improving maternal knowledge and attitudes, focus on the identification of factors that influence the practice and how they can be addressed in a participatory manner by all stakeholders in the community. The findings of our study will be useful particularly to those organizations that focus on behaviour change communication interventions, to improve exclusive breastfeeding.

Milinco et al., (2019) studied the prevalence of breastfeeding in a baby friendly pediatric practice. In a pediatric practice in Italy, actions were undertaken to apply the recommendations for a breastfeeding-friendly physician's office and to promote the adoption of a semi-reclined or laid-back maternal position in breastfeeding. Result showed that a total of 265 newborn infants with a gestational age greater than 30 weeks were registered with the pediatric practice, about $18 \%$ of all infants born in Trieste in that period. The rate of exclusive breastfeeding at five months of age was higher than the one reported for the whole infant population of Trieste and of the Friuli Venezia Giulia Region $(62.3 \%$ vs. $42.9 \%$ vs. $30.3 \%$ ) in the same period. The implementation of breastfeeding-friendly pediatric practice and the application of laidback breastfeeding may improve the rate and duration of exclusive breastfeeding.

Tarrant, (2010) conducted a prospective crosssectional study involved the recruitment of women during the antenatal period, with subsequent follow-up of mothers who delivered healthy, term singleton infants, at 6 weeks and 6 months postpartum. Results revealed that breastfeeding initiation rates of the Irish-national and non-Irish-nationals were $47 \%$ and $79.6 \%$, respectively. Factors that were significantly $(\mathrm{P}=0.000)$ associated with both breastfeeding initiation and 'any' breastfeeding at 6 weeks included mothers who were $>$ or $=35$ years, educated to third level, reported positive postnatal encouragement to breastfeed from their partners and had a positive antenatal intention to breastfeed. The maternal negative perception that breastfeeding is an embarrassing way to feed an infant was demonstrated as a major barrier to initiation. The author concluded that breastfeeding initiation and prevalence rates of the Irishnational population remained low and lag considerably behind national and international targets. Inclusion of the partner in breastfeeding promotional initiatives during the antenatal period may be crucial to increase breastfeeding rates in Ireland. Public health 
campaigns that focus on increasing the social acceptability of breastfeeding may prove effective in addressing this cultural barrier.

Shaili et al., (2012) conducted a communitybased cross-sectional study in the field area of RHTC (Rural Health Training Centre) to know the breastfeeding practices of mothers to strengthen the nutritional, immunological, behavioral and economic practices for improving the health of infants. About 500 post-natal mothers having 0-3 years of age group were selected randomly at RHTC in Uttarakhand, pretested, semi- structured questionnaire was used to collect data. The result showed that 93.6 percent were breastfed and 21.37 percent initiated breastfeeding within an hour.

Only 51.3 percent of infants were exclusively breastfed to six months. Colostrum and prolacteal feeds were given to the infants were 87.18 percent and $66.03 \%$ respectively.

It concluded that breastfeeding was popular in rural women through their knowledge about the same needs to be improved. Since their perceptions regarding the feeding practices directly influence the health of the child, therefore, false beliefs \& myths attached to a child's feeding deeply rooted in all strata of community need to be replaced by sound \& scientific messages. Undesirable cultural practices such as late initiation of breastfeeding, pre-lacteals were more prevalent among the community and mothers have less knowledge regarding breastfeeding practices. Therefore, breastfeeding mothers needs active support, privacy, care during prenatal care followed by birth not only for the communities but also for the entire health system.

\section{Materials and Methods}

For achieving the objectives of the study, a random selection of 300 nursing mothers was done from the Ferozepur district of Punjab which was further divided into six different blocks (Guruharsahai, Zira, Makhu, Ghalkhurd, Mamdot and Ferozepur cantt) including approximately 50 nursing mothers from each block respectively.

The respondents were administered with a prestructured non-disguised questionnaire validated through a pilot survey to fill out a brief survey about the maternal background information, mother's awareness, mother knowledge, attitude of nursing mothers, information regarding breast feeding in hospitals, home, public places, breast feeding practices among mothers, types of supplementary foods given to the child, prevalence of breastfeeding practices and child disease incidences.

For collecting data from the nursing mothers, the respondents were administered with a prestructured non-disguised questionnaire to assess their awareness, knowledge, attitude and practices regarding breast feeding and their various practices.

The data obtained from the survey was analyzed using various statistical tools such as frequency; percentage, mean and standard deviation were used. Apart from these tools, independent $\mathrm{Z}$ Test, one way ANOVA were used for obtaining results. ANOVA was used to find out whether significant difference is there on the basis of means variables such as awareness, knowledge, attitude and practices scores across various categories formed on the basis of age, income, family size, education and $\mathrm{Z}$ test was used for finding whether the obtained means were different from the midpoint of various rating scales used in the questionnaire.

\section{Results and Discussion}

Surveys were conducted to assess the various aspects of mother's awareness, their 
knowledge, attitude, information regarding breastfeeding in different places, breast feeding practices among them, types of supplementary foods given to the child, prevalence of breast-feeding practices and child diseases incidences respectively.

Breast milk is recommended as the infant's sole source of nutrition for the first 6 months of life. It is recommended that complementary foods be added to the infant's diet at 6 months of age and that breastfeeding continue up to two years of age and beyond (2). The above table 4.5 represents breastfeeding practices among mothers.

All the nursing mothers (100\%) think that early initiation of breastfeeding is important for their infants. Additionally, offering colostrums to the baby after delivery, exclusive breastfeeding to the baby under 6 months of age and "breast feeding the baby continuously for one year" nursing mothers shows $100 \%$ agreement to these various breastfeeding statements. A study from Ghana with a large sample size of 10,947 infants concluded that the promotion of early initiation of breastfeeding has the potential to make a major contribution. Up to $16 \%$ of neonatal deaths can be saved, if all infants are breast-fed from day one. Up to 22 percent of the infants' deaths can be prevented if breastfeeding should be started within the first hour of birth (Karen et al., 2006) On contrary to this when the nursing mother were asked regarding the bottle feeding to a child they did not shows their agreement towards this statement. Moreover, to this, the timings regarding complementary feeding for their infants were asked to the nursing mothers. The results shows that majority (77.3\%) of the nursing mothers give complementary feeding 2 to 4 times a day while $65 \%$ of them gives feeding 4 to 6 weeks a day respectively.
Similarly, the other study reported that the majority of the mothers started supplementary feed at 4-6 months of age and the reasons given by them were; insufficient milk, to calm down the baby and believed that breast milk alone is insufficient for a growing baby. Reports indicated that insufficient milk supply was the most common reason cited by the women for weaning (Chen and Chi 2003; Otsuka et al., 2008).

Most of the nursing mothers (55.7\%) shows agreement that a baby should be breast fed at least 6 to 8 times a day while $38.7 \%$ of the nursing mothers agreed that babies should be breast fed more than 8 times a day. Breastfeeding practices were assessed based on the World Health Organization indicators for assessing infant and young child feeding practices (WHO, 2008). Infant feeding practices assessed in this study were defined as follows;

\section{Early initiation of breastfeeding}

Proportion of children born in the last 24 months who were put to the breast within one hour of birth

\section{Exclusive Breastfeeding under 6 months}

The proportion of infants $0-5$ months of age who were exclusively breastfed in the last $24 \mathrm{~h}$

\section{Continuous breastfeeding at 1 year}

Proportion of children 12-15 months of age who are fed breast milk in the last $24 \mathrm{~h}$

\section{Timely complementary feeding}

Proportion of infants 6-8 months of age who were breastfeeding and receiving solid, semisolid or soft foods. 
Table.1 Breast Feeding Practices Among Mothers

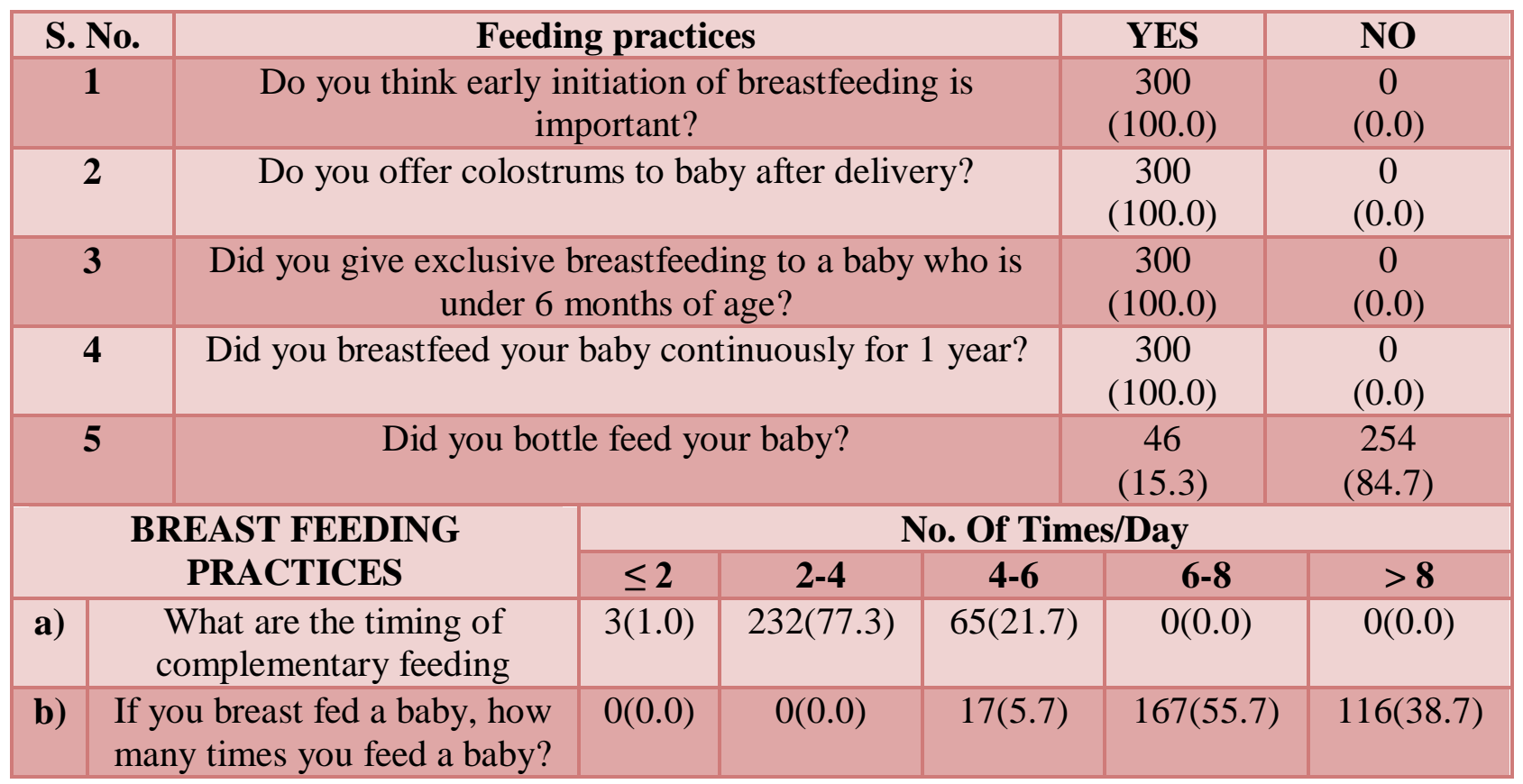

Table.2 Prevalence of Breastfeeding Practices Among Mothers

\begin{tabular}{|c|c|c|c|c|c|c|}
\hline $\begin{array}{l}\text { S. } \\
\text { No }\end{array}$ & Questions / Statements & $\begin{array}{l}\text { Strongly } \\
\text { Agree }\end{array}$ & Agree & $\begin{array}{l}\text { Neither } \\
\text { agree or } \\
\text { disagree }\end{array}$ & Disagree & $\begin{array}{l}\text { Strongly } \\
\text { Disagree }\end{array}$ \\
\hline 1 & $\begin{array}{l}\text { Breast milk gives } \\
\text { immunity to the baby? }\end{array}$ & $\begin{array}{c}75 \\
(25.0)\end{array}$ & $\begin{array}{c}210 \\
(70.0)\end{array}$ & $\begin{array}{c}12 \\
(4.0)\end{array}$ & $\begin{array}{c}0 \\
(0.0)\end{array}$ & $\begin{array}{c}3 \\
(1.0)\end{array}$ \\
\hline 2 & $\begin{array}{l}\text { Breast milk gives enough } \\
\text { water for the baby? }\end{array}$ & $\begin{array}{c}78 \\
(26.0)\end{array}$ & $\begin{array}{c}174 \\
(58.0)\end{array}$ & $\begin{array}{c}48 \\
(16.0)\end{array}$ & $\begin{array}{c}0 \\
(0.0)\end{array}$ & $\begin{array}{c}0 \\
(0.0)\end{array}$ \\
\hline 3 & $\begin{array}{l}\text { Breast milk helps brain } \\
\text { development of the baby? }\end{array}$ & $\begin{array}{c}45 \\
(15.0)\end{array}$ & $\begin{array}{c}123 \\
(41.0)\end{array}$ & $\begin{array}{c}132 \\
(44.0)\end{array}$ & $\begin{array}{c}0 \\
(0.0)\end{array}$ & $\begin{array}{c}0 \\
(0.0)\end{array}$ \\
\hline 4 & $\begin{array}{l}\text { Breastfed babies gain } \\
\text { weight slowly? }\end{array}$ & $\begin{array}{c}12 \\
(4.0)\end{array}$ & $\begin{array}{c}193 \\
(64.3)\end{array}$ & $\begin{array}{c}51 \\
(17.0)\end{array}$ & $\begin{array}{c}44 \\
(14.7)\end{array}$ & $\begin{array}{c}0 \\
(0.0)\end{array}$ \\
\hline 5 & $\begin{array}{c}\text { Breastfeeding is the most } \\
\text { cost-effective way to } \\
\text { protect baby from } \\
\text { diarrheal diseases? }\end{array}$ & $\begin{array}{c}30 \\
(10.0)\end{array}$ & $\begin{array}{c}176 \\
(58.7)\end{array}$ & $\begin{array}{c}91 \\
(30.3)\end{array}$ & $\begin{array}{c}3 \\
(1.0)\end{array}$ & $\begin{array}{c}0 \\
(0.0)\end{array}$ \\
\hline 6 & $\begin{array}{l}\text { Breastfeeding protects } \\
\text { mother from breast } \\
\text { cancers? }\end{array}$ & $\begin{array}{c}0 \\
(0.0)\end{array}$ & $\begin{array}{c}156 \\
(52.0)\end{array}$ & $\begin{array}{c}123 \\
(41.0)\end{array}$ & $\begin{array}{c}0 \\
(0.0)\end{array}$ & $\begin{array}{c}21 \\
(7.0)\end{array}$ \\
\hline 7 & $\begin{array}{l}\text { Breastfeeding affects } \\
\text { mother's health badly? }\end{array}$ & $\begin{array}{c}0 \\
(0.0)\end{array}$ & $\begin{array}{c}21 \\
(7.0)\end{array}$ & $\begin{array}{c}62 \\
(20.7)\end{array}$ & $\begin{array}{c}189 \\
(63.0)\end{array}$ & $\begin{array}{c}28 \\
(9.33)\end{array}$ \\
\hline
\end{tabular}




\section{Bottle feeding}

The proportion of infants less than 24 months of age who were receiving any food or drink from a bottle in the last $24 \mathrm{~h}$. It is evident from the above table 4.7 that most of the nursing mothers $(70 \%)$ agreed towards the statement that "Breast milk gives immunity to the baby" while 25 percent of the mothers showed strong agreement towards it.

Nearly half of the nursing mothers (58\%) showed agreement that "breast milk gives enough water for the baby" followed by 26 percent of them showing strong agreement to the above statement. Furthermore, when it comes to the statement regarding that "breast milk helps brain development of the baby" 41 percent of the nursing mother showed agreement while the other 44 percent neither agreed or disagreed towards this statement. In addition to this around half of the nursing mothers $(52 \%)$ and 41 percent of them neither agreed or disagreed regarding the statement that "breastfeeding protects mother from breast cancers".

The statement "Breastfeeding is the most costeffective way to protect baby from diarrheal diseases" showed various opinions out of which 58.7 percent were agreed, 10 percent strongly agreed and 30 percent of the mothers were neither agree or disagreed pertaining to this statement respectively. Similarly, the other statement "breastfed babies gain weight slowly" also showed various opinions out of which nursing mother 64 percent showed agreement, 17 percent were neither agree or disagreed while 14.7 percent showed disagreement. On contrary to this when a question was raised regarding "breastfeeding affects mother's health badly" 63 percent of the mothers showed disagreement while 20.7 percent of them were neither agree or disagree towards the statement. According to Oddy et al., 2010 breastfeeding promotes health for both mother and infant and helps to various prevent diseases. Longer breastfeeding promotes better mental health through childhood and into adolescence. Similarly it was also reported that breastfeeding appears to reduce the risk of extreme obesity in children. (Armstrong and Reilly, 2002).

The rate of exclusive breastfeeding in India continues to be sub-optimal with no appreciable gains in the last ten to fifteen years. Interventions that seek to increase exclusive breastfeeding should be timely with an increased focus on mothers with infants four to six months of age and in those who are most at risk of early discontinuation of exclusive breastfeeding.

\section{Acknowledgement}

This research paper is the output of Minor Research Project entitled 'Breast Feeding: A Step towards Healthy and Productive Life' supported by Impress, ICSSR, New Delhi.

\section{References}

Alison Mc-Fadden, Siebelt L, Marshall J. L., Gavine A., Girard Lisa-Christine, Symon A., and Stephen Mac-Gillivray (2019) Counselling interventions to enable women to initiate and continue breastfeeding: a systematic review and meta-analysis. Inter Breast feeding J 14(42):1-19.

Afrose, L., B. Banu, K. R. Ahmed and K. Khanom. (2012) Factors associated with knowledge about breastfeeding among female garment workers in Dhaka city. WHO South East Asia J. Public Health 1(3): 249.

American Academy of Pediatrics (2012) Policy Statement: breastfeeding and the use of human milk. Pediatrics129: e827-e41.

Armstrong, J., Reilly, J. J. (2002). Breastfeeding and lowering the risk of childhood obesity, Lancet.359 (9322): 2003-4.

Chandhiok, $\mathrm{N}$ et al., (2015) Changes in exclusive breastfeeding practices and its determinants 
in India, 1992-2006: analysis of national survey data International Breastfeeding Journal volume 10, Article number: 34 (2015)

Chen C. H. and Chi C. S. (2003) Maternal intention and actual behavior in infant feeding at one month postpartum. Acta Paediatr Taiwan. 44(2):140-4.

Joseph Singh, et al., (2012) Breastfeeding practices among lactating mothers: Problems and prospects in a cross-sectional study. Int $J$ Health Allied Sci 2012; 1:54-8

Karimi, B., M. Z. Sani, R. Ghorbani and N. Danai. (2014) The pregnant mothers' knowledge about breastfeeding in Semnan, Iran. Middle East J. Rehabil. Health 1(1): 20833

Kramer M. S., Guo T., Platt R. W., Sevkovskaya Z., Dzikovich I., Collet J. P., et al., (2003) Infant growth and health outcomes associated with 3 compare with 6 mo of exclusive breastfeeding. Am J Clinical Nutr. 78(2):291-5.

Karen M. E, Charles Z, Maria A. Q, Seeba A.-E, Seth O-A, Betty R. K. (2006) Delayed Breastfeeding Initiation Increases Risk of Neonatal Mortality. Pediatrics 117(3):38086.

Milinco, et al., (2019) Prevalence of breastfeeding in a baby-friendly pediatric practice: an experience in Trieste, Italy. International Breastfeeding Journal 26:239-34.

Mohamed M. J., Ochola S and Owino V. O. (2018) Comparison of knowledge, attitudes and practices on exclusive breastfeeding between primiparous and multiparous mothers attending Wajir District hospital, Wajir County, Kenya: a cross-sectional analytical study. Int Breastfeeding $J$ 13(11):1-10.

Oddy, Wendy H, Kendall G. E., Li, J, Robinson J.
P, Klerk M, Silburn N. H, Zubrick S.R, Landau L. I. and Stanley, F. J. (2010) The long-term effects of breastfeeding on child and adolescent mental health: a pregnancy cohort study followed for 14 years, $J$ Pediatrics156 (4): 568-574.

Roy S, Simalti A. K, Nair B. T. (2018) Prevalence of Exclusive Breastfeeding and Knowledge Related to Breastfeeding among Mothers Attending Immunization Center and Well baby Clinic. Acta Medica Inter 5(2):79-83.

Shaili V, Sharma Parul, Kandpal S D, Semwal Jayanti, Srivastava Anurag, Nautiyal Vipul (2012) A community-based study on breastfeeding practices in a rural area of uttarakhand. Nat J Community Medicine 3(2):283-287.

Tarrant R C, et al., (2012). Mothers who formula feed: their practices, support needs and factors influencing their infant feeding decision. Child Care in Practice.19(1):7894.

WHO, UNICEF (1993) Breastfeeding counselling: a training course? Geneva: World Health Organization; 1993.

World Health Organization (2008) Indicators for assessing infant and young child feeding practices: conclusions of a consensus meeting held 6-8 November 2007 in Washington D.C., USA. Geneva: World Health Organization.

WHO, UNICEF (2018). The extension of the 2025 maternal, infant and young child nutrition targets to 2030. Geneva: World Health Organization.

World Health Organization (2009) Infant and young child feeding: model chapter for textbooks for medical students and allied health professionals. Geneva: World Health organisation

\section{How to cite this article:}

Vandana Gupta. 2021. Prevalence of Breast-Feeding Practices Among Post Natal Mothers. Int.J.Curr.Microbiol.App.Sci. 10(10): 614-621. doi: https://doi.org/10.20546/ijcmas.2021.1010.071 